\title{
Nazobiliyer drenaj halen etkin ve güvenilir bir yöntemdir: Şiş̧li Etfal Hastanesi deneyimi
}

Nasobiliary drainage is still an effective and reliable treatment modality: Şişli Etfal Hospital experience

Meltem ERGÜN, Ali Rıza KÖKSAL, Salih BOĞA, Mehmet BAYRAM, Engin ALTINKAYA, Osman ÖZDOĞAN,

Hüseyin ALKIM, Canan ALKIM

Şişli Etfal Eğitim ve Araşstırma Hastanesi, Gastroenteroloji Kliniği, Istanbul, Türkiye

Giriş ve Amaç: Nazobiliyer drenaj, akut süpüratif kolanjit, safra yollarına açılmış kist hidatik ve postoperatif safra kaçaklarında endoskopik tedavi metodu olarak kullanılmaktadır. Biz de kliniğimizde nazobiliyer drenaj kateterinin etkinliği ve güvenilirliğini retrospektif olarak incelemeyi amaçladık. Gereç ve Yöntem: Ocak 2011 ile Aralık 2012 arasında Şişli Etfal Eğitim ve Araştırma Hastanesi Gastroentereoloji Kliniği Endoskopi ünitesinde nazobiliyer drenaj kateteri takılmış olan 22 hasta çalışmaya alındı. Hastaların demografik özellikleri, laboratuvar değerleri, hastalara yapılan işlemler, işlem sonrası klinik seyir ve işlem komplikasyonları retrospektif olarak değerlendirildi. Bulgular: Nazobiliyer drenaj kateteri 12-84 yaş arası (Ortalama 54,3 土24,4) 22 hastaya (11 kadın) takılmıştır. Akut süpüratif kolanjit nedeniyle 11 hastaya, safra yollarına açılmış kist hidatik nedeniyle 4 hastaya, postoperatif kaçak nedeniyle 3 hastaya, eksternal safra kaçağı sebebiyle 2 hastaya ve hemobilia nedeniyle 2 hastaya nazobiliyer drenaj kateteri uygulaması yapıl-

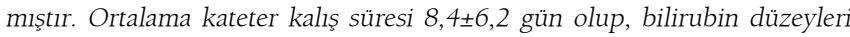
normalizasyonu da 4ะ0,6 günde gerçekleşmiştir. Hastaların tamamı nazobiliyer drenajın konforsuz bir tedavi şekli olduğunu ifade etseler de, hiçbirinde nazobiliyer kateter dislokasyonu gerçekleşmemiştir. Endoskopik retrograd kolanjiyopankreatografi işlemi ile ilişkili komplikasyon ve mortalite saptanmamıştır. Sonuç: Nazobiliyer drenaj akut süpüratif kolanjit, postoperatif safra kaçağı, safra yollarına açılmış kist hidatikte etkin ve güvenilir bir tedavi yöntemidir.

Anahtar kelimeler: Nazobiliyer drenaj, kolanjit, safra kaçă̆ı

\section{GİRIŞ}

Nazobiliyer drenaj (NBD) tekniği, 1976'dan beri obstrüktif sarılık tedavisinde kullanılmaktadır (1). Biliyer drenajı temin etmek amacıyla plastik, metalik, kaplı, kapsız stentler kullanıma girse de, NBD halen endoskopik retrograd kolanjiyopankreatografi (ERCP) pratiğinde başarılı şekilde kullanılmaktadır. Özellikle akut süpüratif kolanjit, safra yollarına açılmıs kist hidatik gibi koyu safra, membran, kan drenajı olan olgularda işlem sonrası biliyer drenajı temin etmede NBD oldukça başarılıdır $(2,3)$. Aralıklarla kateterin yıkanabilmesi ve gerektiğinde opak madde verilerek görüntüleme yapılabilmesi bu tekniğin avantajlarını oluşturmaktadır.

Çalışmamızın amacı Ocak 2011 ile Aralık 2012 tarihleri arasinda endoskopi ünitemizde NBD takılan hastalardaki tedavi başarısını retrospektif olarak değerlendirmektir.

Ergün M, Köksal RA, Boğa S, et al. Nasobiliary drainage is still an effective and reliable treatment modality: Şişli Etfal Hospital experience. Endoscopy Gastrointestinal 2014; 22: 8-10.
Background and Aims: Nasobiliary drainage is an established mode of treatment for acute suppurative cholangitis, bile leakage and biliary fistula. We retrospectively analyzed the safety and efficacy of nasobiliary drainage placement for biliary drainage in patients with acute cholangitis. Materials and Methods: Between January 2011 and December 2012, nasobiliary drainage was performed in 22 patients at Sişli Etfal Training and Education Hospital. The clinical characteristics, laboratory results, clinical outcomes, and complications were analyzed retrospectively. Results: Nasobiliary drainage was performed in 22 patients ( 11 female), and the mean age was $54,3 \pm 24,4$ years (range, 12-84). Acute suppurative cholangitis ( $n=11)$, hydatid cyst with biliary communication $(n=4)$, postoperative biliary leak $(n=3)$, external biliary leakage $(n=2)$, and hemobilia $(n=2)$ were the main indications of nasobiliary drainage. The catheter was removed in $8,4 \pm 6,2$ days, and time elapsed to normalization of total serum bilirubin levels was $4 \pm 0,6$ days. There were no endoscopic retrograde cholangiopancreatography -related complications. Although it is not a comfortable treatment modality, there were no instances of displacement or kinking of the nasobiliary drainage. Conclusions: Biliary drainage by nasobiliary drainage is a safe and effective treatment in patients with severe cholangitis, postoperative bile leakage and bile fistula.

Key words: Nasobiliary drainage, cholangitis, biliary leakage

\section{GEREÇ VE YÖNTEM}

Ocak 2011 ile Aralık 2012 tarihleri arasında Șişli Etfal Hastanesi Gastroenteroloji Kliniği Endoskopi Ünitesinde NBD kateteri takılmış olan 22 hasta 12-84 yaş arası (Ortalama 54,3 $\pm 24,4) 22$ hasta (11 kadın) çalışmaya alındı.

Hastalık etiyolojileri değerlendirildiğinde 11 hastada akut sü-
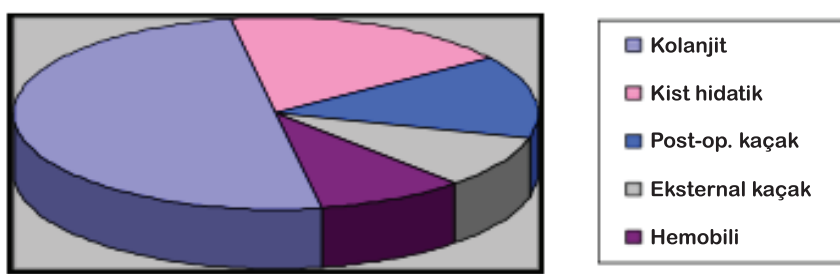

Şekil 1. Etyolojilerine göre NBD kateteri takılma oranları Geliş Tarihi: 10.03.2014 Kabul Tarihi: 31.03.2014 


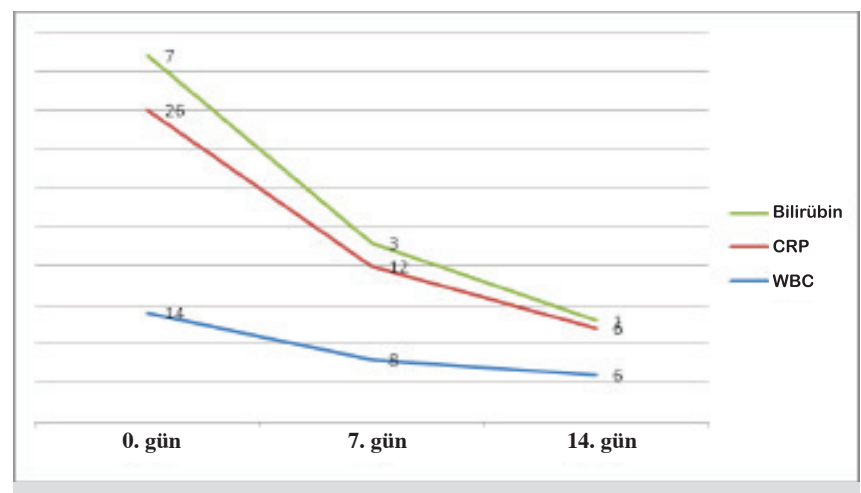

Şekil 2. Laboratuvar incelemelerinde hastalığın seyri boyunca olan değişimler

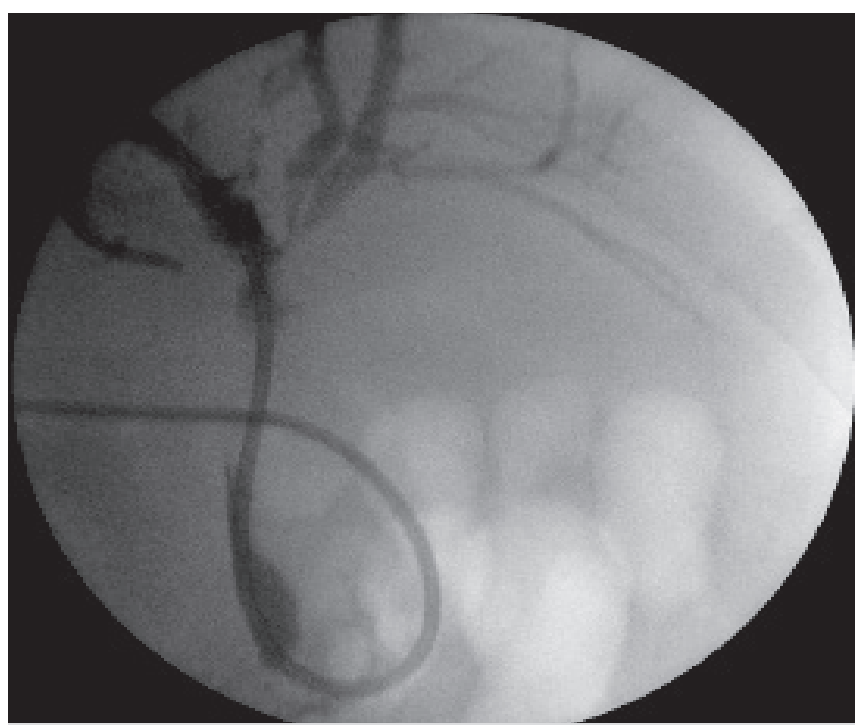

Resim 1. Kolanjiokarsinom nedeniyle ciddi akut kolanjit geçiren bir hastada nazobiliyer drenaj kateterin radyolojik görüntüsü

\begin{tabular}{|c|c|}
\hline Yaş & Ortalama $54,3 \pm 24,4(12-84$ yaş aralığı) \\
\hline Cinsiyet & $11(\% 50)$ kadın \\
\hline Sağ üst kadran ağrısı & 20 \\
\hline Ateş & 18 \\
\hline Sarılık & 17 \\
\hline Geçirilmiş kolesistektomi & 3 \\
\hline ERCP öyküsü & 5 \\
\hline
\end{tabular}

Tablo 2. Başlangıç laboratuvar değerleri: Ortalama (Standart sapma)

$\begin{array}{ll}\text { Total lökosit sayısı x 109/L } & 14.600(1106) \\ \text { CRP }(0-5 \mathrm{mg} / \mathrm{L}) & 26(36) \\ \text { AST }(0-35 \mathrm{U} / \mathrm{L}) & 148(12) \\ \text { ALT }(0-45 \mathrm{U} / \mathrm{L}) & 156(14) \\ \text { ALP }(30-120 \mathrm{U} / \mathrm{L}) & 194(32) \\ \text { GGT }(0-42 \mathrm{U} / \mathrm{L}) & 172(42) \\ \text { Bilirübin }(0,3-1,2 \mathrm{mg} / \mathrm{dL}) & 6.8(2.6) \\ \text { Albümin }(3,5-5,2 \mathrm{~g} / \mathrm{dL}) & 3.2(0.6)\end{array}$

CRP: C reaktif protein, AST: Aspartat aminotransferaz, ALT: Alanin aminotransferaz, ALP: Alkalen fosfataz, GGT: Gama glutamil transferaz. püratif kolanjit, 4 hastada safra yollarına açılmış kist hidatik, 3 hastada postoperatif safra kaçağı, 2 hastada eksternal safra kaçağı ve 2 hastada da hemobilia mevcuttu (Şekil 1).

Akut süpüratif kolanjit tanısı temel olarak Charcot triadına (ateş, sarılık, sağ üst kadran ağrısı) göre konuldu. Eşlik eden septik şok ve mental durumda bozulma (Raynoud pentadı), koledoktan püy drenajı olması da hastalığın ciddiliği yönünden yardımcı tanı kriterleri olarak kullanıldı. Retrospektif olarak incelendiğinde hastaların tamamının Tokyo kriterlerine göre kesin veya olası kolanjit grubunda olduğu belirlendi (4). Tüm hastalar IV antibiyotik tedavisi, IV hidrasyon tedavisi aldı. Hospitalizasyonu takiben ilk 12 saat içinde ERCP işlemi yapıldı. ERCP işlemi tecrübeli endoskopistler tarafından yandan görüşlü duodenoskop ile (JF-240, JF-260V; Olympus Optical, Tokyo, Japan) yapıldı. Endoskopik sfinkterotomi, balon ve/veya basket kateter yardımıyla taş çıkarılması işlemi süpüratif kolanjitli hastaların tamamına uygulandı. NBD kateteri (Wilson Cook Medical, Inc, Winston-Salem, NC) 7 F kullanildı.

\section{BULGULAR}

NBD kateteri 12-84 yaş arası (Ortalama 54,3 $\pm 24,4) 22$ hastaya (11 kadın) takılmıştır. Hastaların çoğu sağ üst kadran ağrısı, ateş ve sarılık şikayetleri ile hastaneye başvurmuş olup, klinik prezentasyonlar ve laboratuvar parametreleri Tablo 1 ve 2'de belirtilmiştir. Hastaların tamamına ilk görüntüleme tekniği olarak ultrasonografi uygulanmış, 17 hastaya ise abdominal tomografi veya manyetik rezonans görüntüleme yapılmıştır. Akut süpüratif kolanjit nedeniyle 11 hastaya NBD kateteri takılmış ve bu gruptaki 6 hastada koledokolitiasis ve 5 hastada ise koledok malign darlığı tespit edilmiştir. Safra yollarına açılmış kist hidatik nedeniyle 4 hastaya, postoperatif kaçak nedeniyle 3 hastaya, eksternal safra kaçağı sebebiyle 2 hastaya ve hemobilia nedeniyle 2 hastaya NBD kateteri uygulaması yapılmıştır (Şekil 1). Isşlem esnasında koledoktan püy gelmesi 10 hastada tespit edilmiştir. Ortalama kateter kalış süresi $8,4 \pm 6,2$ gün olup, bilirübin düzeyleri normalleşmesi de 4ะ0,6 günde gerçekleşmiştir. Laboratuvar değerlerinin seyri Şekil 2'de belirtilmiştir. Ciddi akut kolanjit nedeniyle yapılan nazobiliyer drenaj radyolojik görüntüsü Resim l'de gösterilmiştir.

Hastaların tamamı nazobiliyer drenajın konforsuz bir tedavi şekli olduğunu ifade etseler de, hiçbirinde nazobiliyer kateter dislokasyonu gerçekleşmemiştir. ERCP işlemi ile ilişkili komplikasyon ve mortalite saptanmamıştır.

\section{TARTIŞMA}

Bizim çalışmamız nazobiliyer drenajın akut süpüratif kolanjit, safra yollarına açılmış kist hidatik ve postkolesistektomi safra kaçaklarının tedavisinde başarılı bir tedavi yöntemi olduğunu göstermiștir. Hastalarımızda ERCP işlemine bağlı komplikasyon saptanmayıp, NBD kateterine bağlı rahatsızlık 
hissi tüm hastalarda tariflenmiştir. Kolanjit hastaların tamaminda yaklaşık bir haftada gerilemiştir.

Safra drenajının taş, tümör gibi nedenlerle bozulduğu durumlarda safra yolları içinde basınç artarak kolanjiovenöz ve/ veya kolanjiolenfatik reflü ortaya çıkmaktadır. Bu durumda endotoksemi ve septisemi oluşmaktadır (5). Safra yolu drenajının sağlanmasında en etkili yöntem ERCP işlemidir. Cerrahi metodun bu hastalarda yüksek mortalite ve morbiditesi olduğu bilinmektedir. Perkütan yöntemin de işlem sonrası komplikasyon oranları yüksektir $(6,7)$. ERCP ile drenaj işleminde sfinkterotomi ardından taş ekstraksiyonu yapılması koledokolitiazisde standart yöntemdir. Ancak süpüratif kolanjitte, püy drenajı olduğunda yahut kist hidatikteki gibi membranlar ekstrakte edildiğinde işlem sonrası safra drenajının devamını temin etmek amaciyla NBD veya biliyer stent kullanımı gündeme gelmektedir (8). Ayrıca zor taşlarda, büyük taşlarda ve çok sayıda taşı olan hastalarda koledokun temizliği tek seansta mümkün olmayabilir veya işlem süresi çok uzayabilir. Bu durumlarda da işlemi NBD kateteri koyarak veya stent yerleştirerek bitirmek endoskopistlerce tercih edilen bir yöntem olmuştur (9). Koagülopatisi olan hastalarda da sfinkterotomi yapılmadan balon dilatasyonu sonrası NBD/stent konması hastalarda biliyer drenajın sağlanmasında etkindir (10).

Safra drenajının devamını temin etmede NBD kateteri veya plastik stentler kullanılabilir.

NBD kateteri takılmasının avantajları:

1. Hasta takibi esnasında tıkanan NBD kateterinin yıkanarak açılabilmesi,

2. Radyoopak madde verilerek tekrar işleme gerek kalmadan safra drenajının kontrolüne imkan tanıması ve

3. Gerektiğinde yine işleme gerek kalmadan çekilebilmesidir.

\section{KAYNAKLAR}

1. Nagai N, Toki F, Oi I, et al. Continuous endoscopic pancreatocholedochal catheterization. Gastrointest Endosc 1976; 23:78-81.

2. Sharma BC, Reddy RS, Garg V. Endoscopic management of hepatic hydatid cyst with biliary communication. Dig Endosc 2012; 24:267-70.

3. Yang J, Peng JY, Pang EJ, Chen W. Efficacy of endoscopic nasobiliary drainage for the prevention of post-endoscopic retrograde cholangiopancreatography pancreatitis and cholangitis after repeated clearance of common bile duct stones: Experience from a Chinese center. Dig Endosc 2013; 25:453-8.

4. Kiriyama S1, Takada T, Strasberg SM, et al. New diagnostic criteria and severity assessment of acute cholangitis in revised Tokyo Guidelines. J Hepatobiliary Pancreat Sci 2012; 19:548-56.

5. Sharma BC, Agarwal DK. Etiopathogenesis, clinical features and management of acute cholangitis. J Assoc Physicians India 1995; 43:422-6.

6. Magun A. Acute cholangitis - endoscopic drainage or emergency surgery? Gastroenterology 1990; 99:1530-1.

7. Huang SM, Yu SC, Tsang YM et al. Complication of percutaneous transhepatic cholangiography and biliary drainage. J Clin Gastroenterol 1989; 96:446-52
NBD kateterinin dezavantajları ise:

1. İşlem süresini uzatması

2. Oral kaviteden nazal yola geçirirken nadir de olsa zedelenmeye sebep olma ihtimali

3. Uyumsuz hastalarda kateterin yerinden çıkması

4. Hastada rahatsızlık hissi oluşturmasıdır (9-10).

Sharma ve arkadaşlarının akut kolanjitli hastalarda yaptıkları randomize çalışmada NBD kateteri ve plastik stent etkinliği ve güvenilirliği benzer bulunmuştur (11). Lee ve arkadaşlarının çalışmasında ise akut kolanjitli hastalarda safra yolu drenajı tam olarak sağlanmışsa, NBD kateteri takılmasının ek bir fayda sağlamadığı belirtilmektedir (12). Çin'den yakın zamanda yayınlanan bir başka çalışma sonucuna göre özellikle büyük ve çok sayıda taşı olan hastalarda NBD kateteri takılmasının hastanede yatış süresini kısalttığı belirtilmiştir (3).

Postkolesistektomi safra kaçakları ve safra yollarına açılmış kist hidatik tedavisinde hem plastik stentler hem de NBD kateterleri kullanılmaktadır $(13,14)$. Her iki tedavi yöntemi de etkin görülmekle beraber, bu konuda prospektif randomize çalışma bulunmamaktadır.

Kist hidatik hastalarında, kistin safra yoluna açılmasıyla, safra yoluna kist içeriği, membranlar boşalır ve safra drenajını bozarlar. Bu grup hastalarda koledok balon ve basket yardımıyla temizlense de lümende membran parçaları kalabilmekte ve drenajın tekrar tekrar bozulmasına sebep olmaktadırlar. NBD kateteri ile hem drenajın sürekliliği sağlanır hem de biliyer fistüllerin kapanmasına imkan tanınmış olur.

Nazobiliyer drenaj akut süpüratif kolanjit, postoperatif safra kaçağı, safra yollarına açılmış kist hidatikte etkin ve güvenilir bir tedavi metodudur.

8. Kawashima H, Itoh A, Ohno E, et al. Is nasobiliary drainage unnecessary for drainage of acute suppurative cholangitis? Our experience. Dig Endosc 2010; 22 (Suppl 1):S118-22.

9. Horiuchi A, Nakayama Y, Kajiyama M, et al. Biliary stenting in the management of large or multiple common bile duct stones. Gastrointest Endosc 2010; 71:1200-3

10. Park DH, Kim MH, Lee SK, et al. Endoscopic sphincterotomy vs. endoscopic papillary balloon dilation for choledocholithiasis in patients with liver cirrhosis and coagulopathy. Gastrointest Endosc 2004; 60:180-5.

11. Sharma BC, Kumar R, Agarwal N, Sarin SK. Endoscopic biliary drainage by nasobiliary drain or by stent placement in patients with acute cholangitis. Endoscopy 2005; 37:439-43.

12. Lee JK, Lee SH, Kang BK, et al. Is it necessary to insert a nasobiliary drainage tube routinely after endoscopic clearance of the common bile duct in patients with choledocholithiasis-induced cholangitis? A prospective, randomized trial. Gastrointest Endosc 2010 ; 71:105-10.

13. Sachdev A, Kashyap JR, D'Cruz S, et al. Safety and efficacy of therapeutic endoscopic interventions in the management of biliary leak. Indian J Gastroenterol 2012; 31:253-7

14. Sharma BC, Reddy RS, Garg V. Endoscopic management of hepatic hydatid cyst with biliary communication. Dig Endosc 2012; 24:267-70. 